\title{
Testing and optimization of the seismic networks of Campi Flegrei (Southern Italy)
}

\author{
A. Tramelli, C. Troise, G. De Natale, and M. Orazi \\ Istituto Nazionale di Geofisica e Vulcanologia, Sezione di Napoli, Osservatorio Vesuviano, Napoli, Italy
}

Correspondence to: A. Tramelli (tramelli@ov.ingv.it)

Received: 29 May 2013 - Revised: October 2013 - Accepted: 6 November 2013 - Published: 29 November 2013

\begin{abstract}
The definition of the network resolution power is an important parameter to be considered when evaluating most of the seismic analysis, being connected to the location quality and earthquakes detectability.

We estimated the resolving power of the seismic network of Campi Flegrei. The results show that the actual moment magnitude threshold is 0.5 in the Solfatara area, center of the caldera, but increases sharply going away from the center.

We also estimated the theoretical resolution power of the actual seismic network of Campi Flegrei plus 5 hypothetical borehole stations, moving the borehole stations into 3 different wells. As expected, big improvements in the location parameters come from the use of borehole stations. The results show that a $3000 \mathrm{~m}$ deep borehole located close to the actual hypocentral area would allow to detect and locate the very low magnitude earthquakes, probably connected to the hydrothermal system characterizing the Campi Flegrei caldera.

Finally, we performed an optimization analysis of the permanent seismic network of Campi Flegrei finding the best 3 station positions that would increase the resolution power of the network to locate earthquakes in the South and offshore part of the caldera. We evidenced that the actual network has an improvable resolution in the South and West part of the caldera.
\end{abstract}

\section{Introduction}

Seismic network resolution power analysis and optimization are important procedures to understand and improve the data quality before any seismological analysis. In particular, the design of crucial networks, as the monitoring ones, needs a careful plan to take into account different parameters and to choose the best compromise using objective criteria.
Starting from the fundamental problem of seismic location, the faster algorithm to solve it is based on the least squares approach (Geiger, 1912). This algorithm can be used to evaluate the a priori location resolving power of a seismic network, as shown in Doufexopoulou and Korakitis (1992).

Minimizing the location error is the purpose of the seismic network optimization and it is obtained by searching for the network geometry which maximizes a certain function describing the resolving power of a network on seismic location (e.g. Steinberg and Rabinowitz, 2003, and references therein). The criteria for the selection of the best geometry have been discussed by several authors (e.g. Rabinowitz and Steinberg, 1990, 2000; Steinberg and Rabinowitz, 2003) mainly with regard to the D-optimality principle. The selection of the best geometry is a complex procedure which involves several constraints posed by the nature of the terrain, the budget and the primary object of resolution power. The fundamental point for the optimization process is the definition of experimental goals and constrains, as well as the physical relationship between data and model parameters.

In this paper we estimate the resolution power of the seismic network deployed in Campi Flegrei (Southern Italy) by calculating the a priori error location in a volume. Successively, we applied the multiparametric optimization procedure developed by Tramelli et al. (2013) to plan the future improvement of the network.

Testing and optimization analysis has been performed on the seismic network of Campi Flegrei, the high risk volcanic field West to the city of Naples. This area is actually attracting geophysical and administrative interest due to increase in ground uplift rate (http://www.ov.ingv.it/ov/bollettini-campi-flegrei/ Bollettino_Flegrei_2012_12_21.pdf). This condition calls for an improve in the monitoring seismic network that is 
actually poor in the South part of the caldera due to the high cost of offshore seismic station installations.

\section{Analysis of the resolution power of the Campi Flegrei seismic network}

The actual seismic network deployed at Campi Flegrei is designed to detect and locate events with hypocenters at depths of $2-3 \mathrm{~km}$ close to the Solfatara crater (Fig. 1). Its moment magnitude threshold is around 0.5 in the Solfatara-Agnano area (D'Auria et al., 2011) with a vertical error of hundreds of meters. Anyway events of lower magnitude are often recorded by the station SFT alone (Fig. 1). This suggests the presence of other low magnitude earthquakes in areas not well covered by the actual network.

We analyze the theoretical resolving power on seismic location of the actual seismic network of Campi Flegrei using the linearized approach described in Tramelli et al. (2013).

\subsection{Resolution power of the actual seismic network}

We consider the fourteen stations (Fig. 1) of the permanent INGV - Osservatorio Vesuviano seismic network of Campi Flegrei. We simulated earthquakes of a given magnitude spanning a volume of $20 \times 20 \times 6 \mathrm{~km}^{3}$, with $1 \mathrm{~km}$ space, centered in the caldera area, and tested the ability of the network to locate these events.

The arrival times are calculated from each point of a grid with steps of $0.25 \mathrm{~km}$ on the three directions, using the finite difference algorithm as proposed by Lomax et al. (2000). The travel times from each grid point to each seismic stations are then saved in travel-times tables. The 3-D velocity model used for the computation was derived from the merging of two different tomographic models: the SERAPIS model (Judenherc and Zollo, 2004) and the model proposed by Battaglia et al. (2008). The obtained travel times were added with a random Gaussian error with standard deviations of $0.05,0.1,0.2,0.4$ or $1 \mathrm{~s}$, inversely depending on the signal to noise ratio (SNR) value recorded at each station; $0.05 \mathrm{~s}$ is associated to a SNR higher than 4 and $1 \mathrm{~s}$ to a SNR between 2 and 2.5. The values are estimated to almost fit the real resolution power of the network.

Synthetic data set for earthquakes of different magnitudes were built. Theoretical direct waves amplitude were computed using the single corner frequency spectral model of Boatwright et al. (1991). We assumed a stress drop of $0.5 \mathrm{MPa}$, as the average one determined by several authors (De Natale et al., 1987; Del Pezzo et al., 1987), an average rock density of $2 \mathrm{~g} \mathrm{~cm}^{-3}$ and a rupture velocity of $1.35 \mathrm{~km} \mathrm{~s}^{-1}$ (Del Pezzo et al., 1987), as described in Tramelli et al. (2013). The displacement at the source is calculated as the low frequency spectrum, $\Omega$, divided by rupture time, where $\Omega$ is calculated as a function of seismic moment as described in De Natale et al. (1987, p. 899). The amplitude

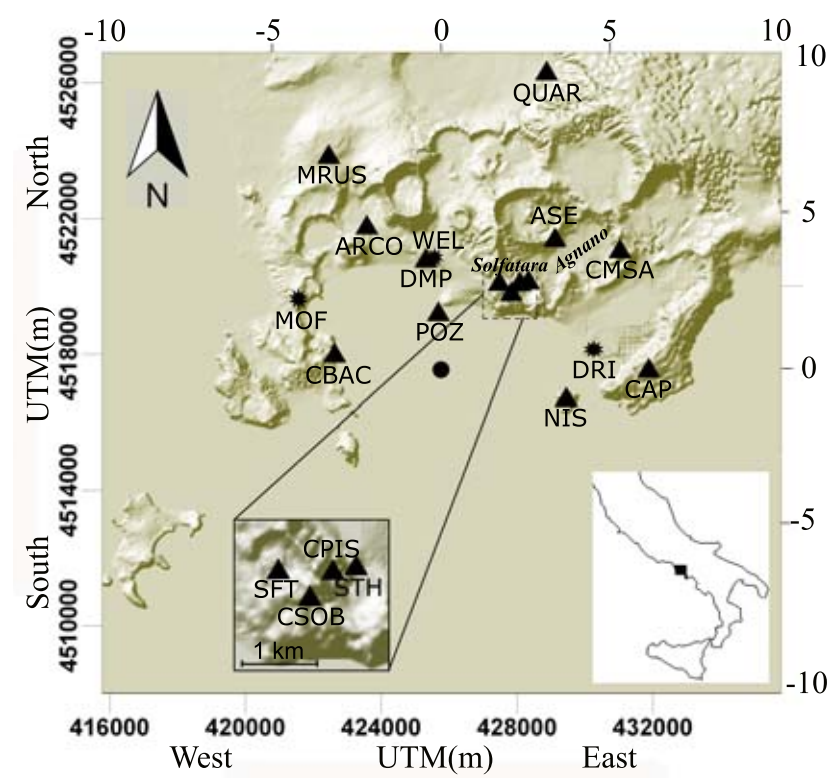

Fig. 1. The Campi Flegrei area, with the stations of the seismic network of the Centro di Monitoraggio of Osservatorio Vesuviano (black triangles). The stars DRI, MOF and WEL indicate the positions of the simulated borehole stations. The black dot indicate the origin of the reference system used in the analysis. In figure both the UTM coordinate in meters (left and bottom axes) and the relative coordinate in kilometers (right and top axes) are reported.

recorded at each station is calculated by attenuating this signal for the geometrical spreading and for the mean attenuation estimated by Petrosino et al. (2008). The noise level at each station was determined as the average amplitude of the recorded noise.

Once the synthetic data set was built, we tested the sensitivity of the network to seismic location in the chosen volume. We evaluated the expected location errors on the three coordinates and on the origin times from covariance matrices. The error on the vertical component obtained for $M_{\mathrm{W}}=0.5$ earthquakes are shown in Fig. $2 \mathrm{a}$.

\subsection{Resolution power of the network with downhole stations}

The high urbanization of the Campi Flegrei area poses serious constraints to the sites availability and to their noise level which is influenced by anthropic, hydrothermal and marine sources (Bruno et al., 2007).

A strong increase in the network sensitivity is then expected adding borehole seismic sensors characterized by significantly lower ambient noise with respect to the surface ones. The addition of borehole sensors would allow to locate also the very low magnitude earthquakes. Downhole stations have the advantage to be, usually, closer to the hypocenters and to record seismic waves that do not cross the highly attenuating shallower levels. Both intrinsic and scattering 

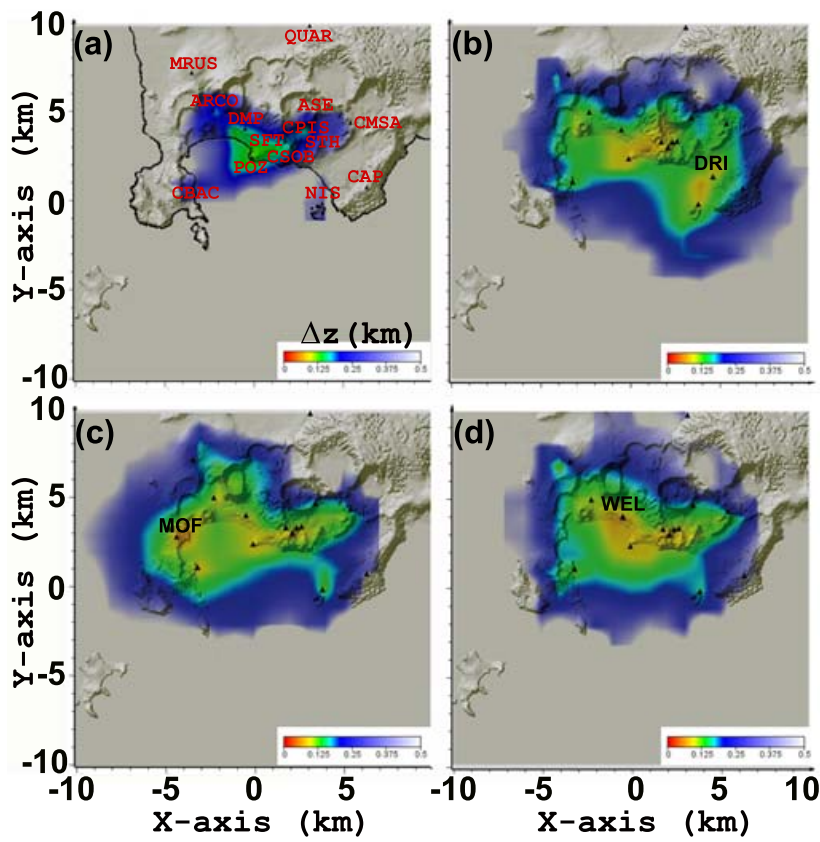

Fig. 2. Location errors (one standard deviation) on the vertical component obtained for earthquakes with $M_{\mathrm{W}}=0.5$. The plan view is referred to the depth of $1 \mathrm{~km}$. Black triangles represent the seismic stations considered for the analysis. In (a) we show the errors computed using the stations of the permanent seismic network. Panel (b) show the errors computed using the actual network plus 5 stations located in a borehole at point DRI; (c) same as (b), but with borehole stations located at point MOF; (d) same as (b), but with borehole stations located at point WEL. A number of 5 seismic stations is considered in each borehole, respectively at depths: 0.25 , 0.6, 1.1, 2.1 and $3.1 \mathrm{~km}$ b.s.1. Axes dimension are $\mathrm{km}$.

attenuation have, indeed, their higher values close to the surface. Consequently the SNR of downhole seismic records are significantly higher with respect to the surface one (Malin et al., 1988; Carter et al., 1991).

We tested the expected location error of the actual seismic network of Campi Flegrei with the addition of 5 borehole stations. Three different borehole locations are considered, separately, for these simulations. The first one is the location of a borehole drilled in the 80's in the area of Mofete, West of the Solfatara, by an Agip-Enel Joint Venture (AGIP, 1987); we will refer to this well as MOF (see Fig. 1). MOF is almost $3000 \mathrm{~m}$ deep and is actually closed and not instrumented. The second location, referred as DRI, is where the pilot hole of the CFDDP project has been drilled, East to the Solfatara, an area which is not well resolved by the actual seismic network (see Fig. 1). The last one, WEL, is a simulated well located close to the area of Solfatara, less than $5 \mathrm{~km}$ to the West, in an area less populated than surroundings, where a scientific borehole could likely be drilled and instrumented (see Fig. 1). In each borehole, five sensors are considered at the depths of $250 \mathrm{~m}, 600 \mathrm{~m}, 1100 \mathrm{~m}, 2100 \mathrm{~m}$ and $3100 \mathrm{~m}$ b.s.l.
To show the improvements that can be obtained adding the borehole stations to the present network, we analyzed the resolution power of the 3 seismic network:

1. actual seismic network (AN) plus 5 stations in DRI,

2. AN plus 5 stations in $\mathrm{MOF}$,

3. AN plus 5 stations in WEL.

The appropriate noise level is associated with each surface site. For each borehole site, the noise level has been lowered with respect to the surface sites by a depth dependent ratio extrapolated by Carter et al. (1991) that shows that the noise recorded at almost $1000 \mathrm{~m}$ is about $3 \mathrm{~dB}$ quieter than the surface one in the $3-6 \mathrm{~Hz}$ frequency band. The parameters are used to define the SNR and hence the quality of the picks.

Results of these computations are shown in Fig. 2b, c and d.

\subsection{Optimization of the network}

We applied the method developed by Tramelli et al. (2013). This method analyses all the possible combinations of station-sites, finding the best set of $\mathrm{M}$ sites for seismic station installation among $\mathrm{N}$ possible choices. The optimal combination is chosen as the one that maximizes a set of assigned conditions.

We applied the optimization method to determine the best sites where to install 3 new seismic stations, in addition to the actual seismic network of Campi Flegrei, to improve the network location capability offshore. We applied the optimization method to identify the best station sites to locate 7 assigned events. We considered the actual permanent seismic network of Osservatorio Vesuviano (first 14 rows in Table 1 and black triangles in Fig. 3a) as initial network. Successively we added 3 station sites chosen between a set of 29 station positions (black diamonds and blue circles in Fig. 3a). We chose these sites as the ones occupied by the mobile seismic network of Osservatorio Vesuviano. We further added the 15 downhole positions in the 3 hypothetical instrumented wells (Fig. 3) described above. Other 5 positions are chosen as actually planned in incoming projects.

We considered $7 M_{\mathrm{W}}=1$ synthetic hypocenters located in the position shown by red stars in Fig. 3a and indicated in Table 2. The synthetic earthquakes are located on the major faults known in the offshore part of the caldera (Orsi et al., 2009) where the offshore seismicity was mainly located during the 1982-84 bradiseismic crises (D'Auria et al., 2011). We assume them to be representative of the offshore local seismicity.

In this case, $7 * 3654$ networks (permutations of 3 stations distributed over 29 sites times 7 earthquakes) have been tested and the determinant of each permutation has been saved. The choice among all the possible networks was made by considering the weighted mean of the determinant obtained for each earthquake, where the weight is associated 
Table 1. Locations of the seismic stations used for the analysis. The right columns show an indicative installation cost (euro) and the mean seismic noise value around $10 \mathrm{~Hz}\left(\mu \mathrm{m} \mathrm{s}^{-1}\right)$ used for the optimization analysis. The installation cost is an estimate performed taking into account the market values for the Campi Flegrei area. The first group of stations (top 14 rows) has been used for the sensitivity analysis. The second group represents the mobile seismic stations actually deployed in the Campi Flegrei area and the third group represents the other possible station positions. The second and third group positions are all used as possible location in the optimization.

\begin{tabular}{|c|c|c|c|c|c|}
\hline Name & Latitude (N) & Longitude (E) & Elev. (m) & Cost & Noise \\
\hline ARCO & $40^{\circ} 50.63^{\prime}$ & $14^{\circ} 5.60^{\prime}$ & 0 & 0 & 1 \\
\hline ASE & $40^{\circ} 50.46^{\prime}$ & $14^{\circ} 9.55^{\prime}$ & 100 & 0 & 0.5 \\
\hline CAP & $40^{\circ} 48.39^{\prime}$ & $14^{\circ} 11.54^{\prime}$ & 170 & 0 & 1 \\
\hline CBAC & $40^{\circ} 48.58^{\prime}$ & $14^{\circ} 4.96^{\prime}$ & 20 & 0 & 1 \\
\hline CMSA & $40^{\circ} 50.29^{\prime}$ & $14^{\circ} 10.91^{\prime}$ & 0 & 0 & 0.5 \\
\hline CPIS & $40^{\circ} 49.75^{\prime}$ & $14^{\circ} 8.82^{\prime}$ & 70 & 0 & 0.5 \\
\hline CSOB & $40^{\circ} 49.59^{\prime}$ & $14^{\circ} 8.64^{\prime}$ & 180 & 0 & 1 \\
\hline DMP & $40^{\circ} 50.11^{\prime}$ & $14^{\circ} 6.85^{\prime}$ & 50 & 0 & 0.5 \\
\hline MRUS & $40^{\circ} 51.75^{\prime}$ & $14^{\circ} 4.79^{\prime}$ & 0 & 0 & 1 \\
\hline NIS & $40^{\circ} 47.92^{\prime}$ & $14^{\circ} 9.82^{\prime}$ & 0 & 0 & 1 \\
\hline POZ & $40^{\circ} 49.26^{\prime}$ & $14^{\circ} 7.12^{\prime}$ & 0 & 0 & 1 \\
\hline QUAR & $40^{\circ} 53.12^{\prime}$ & $14^{\circ} 9.34^{\prime}$ & 0 & 0 & 0.5 \\
\hline SFT & $40^{\circ} 49.75^{\prime}$ & $14^{\circ} 8.39^{\prime}$ & 10 & 0 & 1 \\
\hline STH & $40^{\circ} 49.78^{\prime}$ & $14^{\circ} 9.00^{\prime}$ & 10 & 0 & 0.5 \\
\hline CFSB & $40^{\circ} 47.86^{\prime}$ & $14^{\circ} 07.19^{\prime}$ & -100 & 200000 & 1 \\
\hline CDIO & $40^{\circ} 49.17^{\prime}$ & $14^{\circ} 11.01^{\prime}$ & 150 & 9000 & 1 \\
\hline OMN2 & $40^{\circ} 50.00^{\prime}$ & $14^{\circ} 05.42^{\prime}$ & 40 & 9000 & 1 \\
\hline TAGG & $40^{\circ} 49.76^{\prime}$ & $14^{\circ} 10.42^{\prime}$ & 0 & 9000 & 1 \\
\hline ASB2 & $40^{\circ} 50.61^{\prime}$ & $14^{\circ} 08.75^{\prime}$ & 10 & 9000 & 0.5 \\
\hline CSI2 & $40^{\circ} 50.04^{\prime}$ & $14^{\circ} 07.61^{\prime}$ & 90 & 9000 & 1 \\
\hline AMS2 & $40^{\circ} 49.58^{\prime}$ & $14^{\circ} 09.62^{\prime}$ & 40 & 9000 & 0.5 \\
\hline BGNG & $40^{\circ} 49.13^{\prime}$ & $14^{\circ} 08.72^{\prime}$ & 0 & 9000 & 1 \\
\hline CPBN & $40^{\circ} 48.47^{\prime}$ & $14^{\circ} 09.56^{\prime}$ & 0 & 9000 & 1 \\
\hline CFS1 & $40^{\circ} 48.37^{\prime}$ & $14^{\circ} 09.09^{\prime}$ & 0 & 100000 & 1 \\
\hline CFS2 & $40^{\circ} 50.13^{\prime}$ & $14^{\circ} 06.82^{\prime}$ & -20 & 100000 & 1 \\
\hline CFS3 & $40^{\circ} 50.13^{\prime}$ & $14^{\circ} 06.82^{\prime}$ & -40 & 100000 & 1 \\
\hline CFS4 & $40^{\circ} 50.13^{\prime}$ & $14^{\circ} 06.82^{\prime}$ & -60 & 100000 & 1 \\
\hline FAR0 & $40^{\circ} 50.13^{\prime}$ & $14^{\circ} 06.82^{\prime}$ & 20 & 10000 & 1 \\
\hline DRI1 & $40^{\circ} 48.73^{\prime}$ & $14^{\circ} 10.39^{\prime}$ & -250 & 500000 & 0.3 \\
\hline DRI2 & $40^{\circ} 48.73^{\prime}$ & $14^{\circ} 10.39^{\prime}$ & -600 & 1000000 & 0.2 \\
\hline DRI3 & $40^{\circ} 48.73^{\prime}$ & $14^{\circ} 10.39^{\prime}$ & -1100 & 2000000 & 0.1 \\
\hline DRI4 & $40^{\circ} 48.73^{\prime}$ & $14^{\circ} 10.39^{\prime}$ & -2100 & 6000000 & 0.1 \\
\hline DRI5 & $40^{\circ} 48.73^{\prime}$ & $14^{\circ} 10.39^{\prime}$ & -3100 & 8000000 & 0.1 \\
\hline MOF1 & $40^{\circ} 49.48^{\prime}$ & $14^{\circ} 04.15^{\prime}$ & -250 & 500000 & 0.3 \\
\hline MOF2 & $40^{\circ} 49.48^{\prime}$ & $14^{\circ} 04.15^{\prime}$ & -600 & 1000000 & 0.2 \\
\hline MOF3 & $40^{\circ} 49.48^{\prime}$ & $14^{\circ} 04.15^{\prime}$ & -1100 & 2000000 & 0.1 \\
\hline MOF4 & $40^{\circ} 49.48^{\prime}$ & $14^{\circ} 04.15^{\prime}$ & -2100 & 6000000 & 0.1 \\
\hline MOF5 & $40^{\circ} 49.48^{\prime}$ & $14^{\circ} 04.15^{\prime}$ & -3100 & 8000000 & 0.1 \\
\hline WEL1 & $40^{\circ} 50.13^{\prime}$ & $14^{\circ} 06.82^{\prime}$ & -250 & 500000 & 0.3 \\
\hline WEL2 & $40^{\circ} 50.13^{\prime}$ & $14^{\circ} 06.82^{\prime}$ & -600 & 1000000 & 0.2 \\
\hline WEL3 & $40^{\circ} 50.13^{\prime}$ & $14^{\circ} 06.82^{\prime}$ & -1100 & 2000000 & 0.1 \\
\hline WEL4 & $40^{\circ} 50.13^{\prime}$ & $14^{\circ} 06.82^{\prime}$ & -2100 & 6000000 & 0.1 \\
\hline WEL5 & $40^{\circ} 50.13^{\prime}$ & $14^{\circ} 06.82^{\prime}$ & -3100 & 8000000 & 0.1 \\
\hline
\end{tabular}

with the importance of the earthquake location. We applied an equal weight to all the events as we are looking for a network which well resolves the offshore part of the caldera. We looked for the network associated to the maximum of the mean of determinants and the results are shown in Fig. 3.

\section{Results}

The results of the testing of the Campi Flegrei seismic network are shown in Fig. 2. 
Table 2. Locations of the synthetic hypocenters used in the network optimization, earthquakes are indicated with stars in Fig. 3. The synthetic earthquakes have moment magnitude equal to 1 .

\begin{tabular}{lccc}
\hline $\begin{array}{l}\text { Event } \\
\text { number }\end{array}$ & Latitude (N) & Longitude (E) & $\begin{array}{c}\text { Depth } \\
\text { (m a.s.1.) }\end{array}$ \\
\hline 1 & $40^{\circ} 49.79^{\prime}$ & $14^{\circ} 5.39^{\prime}$ & -1000 \\
2 & $40^{\circ} 49.17^{\prime}$ & $14^{\circ} 6.53^{\prime}$ & -2000 \\
3 & $40^{\circ} 48.04^{\prime}$ & $14^{\circ} 8.60^{\prime}$ & -3000 \\
4 & $40^{\circ} 49.05^{\prime}$ & $14^{\circ} 4.96^{\prime}$ & -1000 \\
5 & $40^{\circ} 48.28^{\prime}$ & $14^{\circ} 7.12^{\prime}$ & -3000 \\
6 & $40^{\circ} 48.52^{\prime}$ & $14^{\circ} 5.87^{\prime}$ & -2000 \\
7 & $40^{\circ} 47.66^{\prime}$ & $14^{\circ} 9.15^{\prime}$ & -3000 \\
\hline
\end{tabular}

Figure 2a shows the contours of the expected location errors on $z$ (depth error) in the considered volume where the earthquakes are distributed on a grid with $\Delta x=\Delta y=\Delta z$ spacing of $1 \mathrm{~km}$.

The resolution is high in the central area of the caldera (Solfatara area) but decreases rapidly with distance, reaching considerably degraded values only $2 \mathrm{~km}$ from the center. It is also evident that the offshore part of the caldera is not well resolved by the actual network. The analysis confirm the actual location threshold of the seismic network which is estimated around magnitude 0.5 in the area of Solfatara (D'Auria et al., 2011).

Figure $2 b, c$ and $d$ show the expected vertical error obtained using the permanent seismic network plus 5 stations in the well DRI (Fig. 2b), MOF (Fig. 2c) and WEL (Fig. 2d). It is evident that the presence of borehole stations improves the network resolution power. Obviously the presence of 5 additionally stations in the network lower the location error because of the increased number of sensors and because the lower they are installed the lower is their background seismic noise. Their spacing influence the location error only if the polarization information are introduced into the inversion process (Tramelli et al., 2013). In the three cases the well resolved area becomes wider, in particular with the wells WEL and DRI that are located in areas that are not well covered by the actual network. Anyway the offshore part of the caldera remains still unresolved.

The application of the sensitivity analysis is fundamental to calibrate all the parameters used in the analysis which will be kept in the optimization analysis. In Fig. 3b we report the optimal network to localize the 7 earthquakes (red stars in Fig. 3a). The network includes the 14 stations of the actual permanent seismic network plus 3 station positions chosen within 29 possible positions. A network optimization performed by the comparison of all possible configurations has the advantage to allow a cost-benefit analyses. In this case, for each station we considered the cost reported in Table 1 as the estimated costs for the sensor purchase, installation and maintenance. In this example we show that we have at least 3 network configurations which are close to be
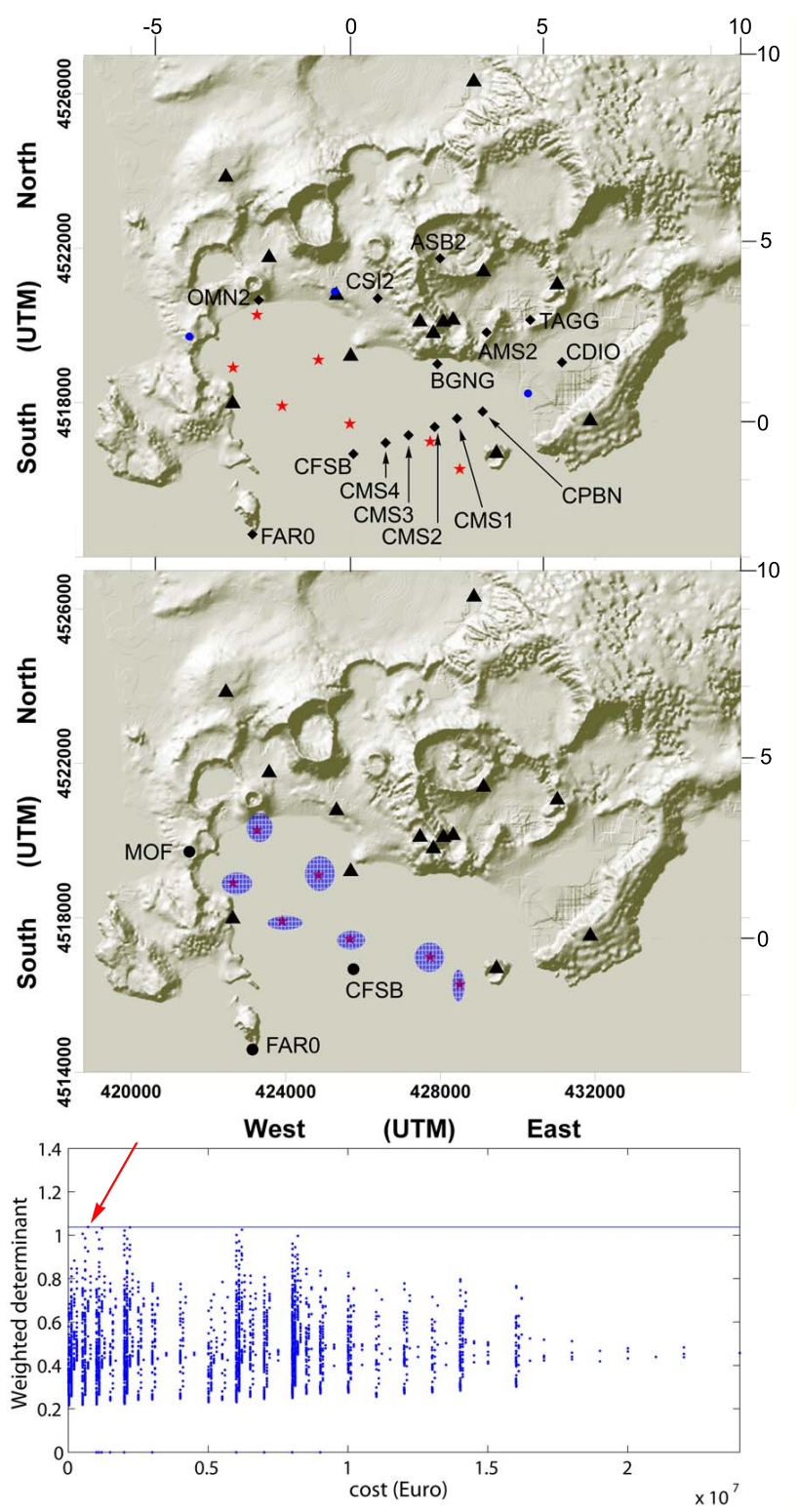

Fig. 3. Results of the optimization analysis performed considering the sites shown by black diamonds and blue ball in panel a and described in Table 1. Black triangle show the stations of the permanent seismic network. The blue circles indicate the position of the 3 wells where 5 station depths are considered (DRI, WEL and MOF). Panel (b) shows the result obtained by choosing the 3 stations (among 29 possible ones, black diamond) that would optimally improve the present network of Campi Flegrei (black triangles) for the location of the 7 earthquakes indicated by the red stars and listed in Table 2. The optimal network is composed by the permanent seismic network plus MOF1, CFSB e FAR0. In (c) we show a cost-to-benefit analysis performed including the installation costs (Table 1) in the list of parameters to be optimized.

optimal. In Fig. 3c we show the cost-determinant function. Looking for the higher determinants, we can choose the one with an affordable cost. Fortunately the best configuration 
(permanent network plus stations CFSB, MOF1 and FAR0) is also not one of the most expensive: 710000 euros. The other 2 networks are composed by the permanent network plus CFSB and FAR0 and station MOF2 or MOF3. These 2 networks will have the advantage to record also lower magnitude events having a lower estimated noise level, but this network improvement will be achieved with a higher effort in terms of costs. It is clear that the network needs a better coverage in the West and South part of the caldera.

\section{Conclusions}

In this work we analyzed the resolution power of the permanent seismic network of Campi Flegrei. The resulting sensitivity, computed with both the methods, depends on the earthquake magnitude, on the network configuration, and on the noise level of the station sites. Also the quality of the velocity model strongly affects the location quality, but in this methods, it influences only the theoretical travel time errors which depend on the event-station distance.

Results obtained in this study clearly indicate the strong improvement in seismic location quality obtained by adding even a single vertical line of borehole seismic sensors (Fig. 2b, c and d). In the Campi Flegrei area, such improvements would help in identifying and locating the very low magnitude earthquakes that are probably connected to the hydrothermal system characterizing the central part of the caldera.

Successively, we looked for the station positions that would improve the Campi Flegrei network resolution offshore. The field experience in the highly populated area of Campi Flegrei taught us that a limited number of stations positions is available. The areas where seismic station can be installed are often municipal properties, as schools. Consequently, in such a case, it is better to analyze any single network combination to take the best advantage from the limited possibilities. We tested all the possible configurations of stations position within a discrete space. The network quality is defined using the determinant of the inverse of the covariance matrix.

In this example we optimized for $M_{\mathrm{W}}=2$ earthquakes, finding that the network needs a better coverage in its South and West part. It is evident that by lowering the magnitude of the earthquakes, the choice of the sites will be constrained to the closest ones, because in the more distant sites the SNR will be too low.

This optimization method was developed to work also for multiparametric networks. The Campi Flegrei volcanic field calls for different monitoring parameters: seismicity, ground deformation, chemical fumarolic composition and cost. The site arrangement requires money and time, consequently a single site is used for different stations sharing the same energy supplies and data transmission equipments. In this example we took into consideration the cost parameter. In this case we notice that the use of expensive borehole stations is not necessary if we want to locate $M_{\mathrm{W}}=2$ offshore earthquakes; the analysis will obviously change when we will lower the earthquake magnitude and will include also the polarization information to the location algorithm. This method allows to discriminate, in an objective way, between different configurations of multiparametric networks.

Acknowledgements. This work has been supported by the European project GEISER and PON-MONICA. We wish to acknowledge A. Delladio and an anonymous reviewer who highly improved the quality of this paper and R. Somma for his helpful suggestions.

\section{References}

AGIP: Geologia e geofisica del sistema geotermico dei Campi Flegrei, Internal Report, 17 pp., 1987.

Battaglia, J., Zollo, A., Virieux, J., and Dello Iacono, D.: Merging Active and Passive Data Sets in Travel-Time Tomography: The Case Study of Campi Flegrei Caldera (Southern Italy), Geophysical Prospecting, 56, 555-573, 2008.

Boatwright, J., Fletcher, B., and Fumal, T. E.: A general inversion scheme for source, site, and propagation characteristics using multiply recorded sets of moderate-sized earthquakes, Bull. Seismol. Soc. Am., 81, 1754-1782, 1991.

Bruno, P. P., G. P. Ricciardi, Z. Petrillo, V. D., Troiano, A., and Chiodini, G.: Geophysical and hydrogeological experiments from a shallow hydrothermal system at Solfatara Volcano, Campi Flegrei, Italy: Response to caldera unrest, J. Geophys. Res., 112, B06201, doi:10.1029/2006JB004383, 2007.

Carter, J., Barstow, N., Pomeroy, P., Chael, E., and Leahy, P.: High frequency seismic noise as a function of depth, Bull. Seismol. Soc. Am., 81, 1101-1114, 1991.

D’Auria, L., Giudicepietro, F., Aquino, I., Borriello, G., Gaudio, C. D., Bascio, D. L., Martini, M., Ricciardi, G. P., Ricciolino, P., and Ricco, C.: Repeated fluid-transfer episodes as a mechanism for the recent dynamics of Campi Flegrei caldera (1989-2010), J. Geophys. Res., 116, B04313, doi:10.1029/2010JB007837, 2011.

De Natale, G., Iannaccone, G., Martini, M., and Zollo, A.: Seismic sources and attenuation properties at the Campi Flegrei volcanic area, PAGEOPH, 125, 883-917, 1987.

Del Pezzo, E., De Natale, G., Martini, M., and Zollo, A.: Source parameters of microearthquakes at Phlegraean fields (Southern Italy) volcanic area, Phys. Earth Planet. Interiors, 47, 25-42, 1987.

Doufexopoulou, M. and Korakitis, R.: Resolution analysis of seismic networks, PEPI, 75, 121-129, 1992.

Geiger, L.: Probability method for the determination of earthquake epicenters from the arrival time only (translated from Geiger's 1910 German article), Bulletin of St. Louis University, 8, 56-71, 1912.

Judenherc, S. and Zollo, A.: The bay of Naples (Southern Italy): Constraints on the volcanic structures inferred from a dense seismic survey, J. Geophys. Res., 109, B10312,doi:10.1029/2003JB002876, 2004.

Lomax, A., Virieux, J., Volant, P., and Berge, C.: Probabilistic earthquake location in 3D and layered models: Introduction of a 
Metropolis-Gibbs method and comparison with linear locations in: Advances in Seismic Event Location, edited by: Thurber, C. H. and Rabinowitz, N., Springer, Kluwer, Amsterdam, 2000.

Malin, P., Waller, J., Borcherdt, R., Cranswick, E., Jensen, E., and Van Schaack, J.: Vertical seismic profiling of Oroville microearthquakes: velocity spectra and particle motion as a function of depth, Bull. Seismol. Soc. Am., 78, 401-420, 1988.

Orsi, G., Vito, M. D., Selva, J., and Marzocchi, W.: Long-term forecast of eruption style and size at Campi Flegrei caldera (Italy), Earth Planet. Sci. Let., 87, 265-276, 2009.

Petrosino, S., Damiano, N., Cusano, P., Veneruso, M., Zaccarelli, L., Torello, V., and Del Pezzo, E.: Seismic noise at Solfatara Volcano (Campi Flegrei, Italy): acquisition techniques and first results, Quaderni di Geofisica, 51, 2008.
Rabinowitz, N. and Steinberg, D.: Optimal configuration of a seismographic network: a statistical approach, Bull. Seismol. Soc. Am., 80, 187-196, 1990.

Rabinowitz, N. and Steinberg, D.: A Statistical Outlook on the Problem of Seismic Network Configuration in: Advances in Seismic Event Location, edited by: Thurber, C. H. and Rabinowitz, N., Kluwer, 51-69, 2000.

Steinberg, D. M. and Rabinowitz, N.: Optimal seismic monitoring for event location with application to on site monitoring of the Comprehensive Test Ban Treaty, Metrika, 31-57, 2003.

Tramelli, A., Troise, C., De Natale, G., and Orazi, M.: A new method for optimization and testing of microseismic networks: an application to Campi Flegrei (Southern Italy), Bull. Seismol. Soc. Am., 103, 1679-1691, 2013. 